\title{
The increasing incidence of initial steroid resistance in childhood nephrotic syndrome
}

\author{
Beata Banaszak • Pawel Banaszak
}

Received: 2 August 2011 /Revised: 23 November 2011 / Accepted: 24 November 2011 /Published online: 10 January 2012

(C) The Author(s) 2012. This article is published with open access at Springerlink.com

\begin{abstract}
Background Recently, a number of reports have highlighted changes in the histopathology and response to corticosteroid treatment in childhood nephrotic syndrome; however, these involved ethnically mixed populations. For comparison, the purpose of our research was to search for changes in the characteristics of nephrotic syndrome in a homogeneous population of Caucasian children over two consecutive decades.

Methods Chart analysis was performed to identify children with new-onset nephrotic syndrome. The children were admitted to the Division of Pediatric Nephrology, Zabrze, during two periods: 1986-1995 (76 patients) and 19962005 (102 patients). Specifically, a comparison of clinical characteristics and morphology of nephrotic syndrome between the two groups was performed. Steroid resistance was defined as no remission within 8 weeks of corticosteroid treatment. Histopathology was available in $36.8 \%$ and $43.1 \%$ of patients respectively.

Results There was a significant increase in primary steroid resistance in the latter decade: $15.8 \%$ vs $31.4 \%(P=0.017)$. Changes in the histopathology did not reach the level of statistical significance: minimal change nephrotic syndrome $25 \%$ vs $9 \%(P=0.095)$, mesangial proliferative glomerulonephritis $46.4 \%$ vs $61.3 \%(P=0.21)$, focal segmental
\end{abstract}

B. Banaszak $(\bowtie)$

Division of Pediatrics in Zabrze, Medical University of Silesia,

Katowice, ul. 3 maja 13/15,

41-800 Zabrze, Poland

e-mail: rhplus@op.pl

P. Banaszak

Department of Congenital Heart Diseases and Pediatric

Cardiology, Silesian Centre for Heart Diseases,

Zabrze, Poland glomerulosclerosis $17.9 \%$ vs $20.4 \%(P=0.78)$, membranoproliferative glomerulonephritis $7.1 \%$ vs $6.8 \%(P=1.0)$, membranous glomerulonephritis $3.6 \%$ vs $0 \%(P=0.39)$.

Conclusions Our results show the increasing incidence of primary steroid resistance in childhood nephrotic syndrome.

Keywords Childhood nephrotic syndrome · Steroid resistance $\cdot$ Steroid sensitivity $\cdot$ Minimal change nephrotic syndrome $\cdot$ Focal segmental glomerulosclerosis

\section{Introduction}

Nephrotic syndrome (NS), caused by massive proteinuria, leading to hypoalbuminemia and edema, seems to be the most common glomerular pathological condition in childhood [1]. Most children who have an NS suffer from idiopathic NS with the histopathology of minimal change glomerulonephritis (MCNS), mesangial proliferative glomerulonephritis (MesPGN) or focal segmental glomerulosclerosis (FSGS) [2-4]. Nephrotic syndromes that are related to the presence of immune complexes in renal tissue include membranoproliferative glomerulonephritis (MPGN), membranous glomerulonephritis (MGN), and others that are rare among children $[3,4]$. In the late 1970s, the International Study of Kidney Disease in Children (ISKDC) and other single-center studies, reported a study on renal biopsies in which most children with primary NS presented with MCNS; other histopathological lesions, including FSGS, were observed in less than $10 \%$ of biopsies [2, 4-7]. Moreover, steroid sensitivity characterized $93-98 \%$ of the population with MCNS examined and $17-30 \%$ of patients with FSGS, translating into an average response to corticosteroids $80 \%$ of children with primary NS [2, 5-7]. Steroid resistance characterized about $20 \%$ of the population 
tested, and late steroid resistance about $3 \%$ of the ISKDC patients [5-7]. On the basis of the ISKDC report, corticosteroids were introduced as a standard treatment of childhood NS $[2,6,7]$.

There is evidence that the characteristics of childhood NS as described above may be invalid now. A number of reports were published on changing trends in the histopathology of NS toward the increasing incidence of FSGS, not only in adults, but also in children [8-16]. Those changes are accompanied by an increase in steroid resistance, as FSGS seems to be strongly related to poor response to corticosteroid therapy. In fact, some reports reveal a significant increase in both primary and secondary steroid resistance in childhood NS compared with the ISKDC data [17]. However, these results could have been altered by the racial composition of populations, as it is widely known that ethnicity plays a role in the epidemiology and histopathology of NS [18-22].

Therefore, the primary objective of our study was to search for changes in characteristics at onset, patients' response to treatment, and a histopathological pattern of childhood NS in a homogeneous population of Caucasian children admitted with new-onset NS to the Division of Pediatric Nephrology in Zabrze (southern Poland) over a period of 20 years (19862005).

\section{Materials and methods}

\section{Patients}

Our approach, based on retrospective chart analysis, was performed in order to identify all children with new-onset NS admitted to the Division of Pediatric Nephrology, Department of Pediatrics in Zabrze, Silesian Medical University, between 1986 and 2005. The institution has been a pediatric nephrology referral center for the region of Silesia (southern Poland) with about 3,900,000 inhabitants before 1999, and about 4,700,000 inhabitants after the territorial reorganization of Poland in 1999. The inclusion criteria comprised:

1. A fulfilled definition of NS

2. Children older than 3 months (to exclude congenital NS) and under 16 years of age

3. New-onset (and untreated) NS or in the initial stages of the standard treatment process

4. Primary NS

5. Minimum of 6 months' follow-up

The exclusion criteria consisted:

1. Non-nephrotic proteinuria

2. Congenital NS
3. NS secondary to metabolic, infectious, vascular, malignant, and cardiac disease

4. Late referrals or already treated NS cases (to avoid referral and selection bias)

Definitions and treatment

By definition, NS comprises heavy proteinuria exceeding $50 \mathrm{mg} / \mathrm{kg} /$ day, hypoalbuminemia $<2.5 \mathrm{~g} / \mathrm{dL}$, hypercholesterolemia, and edema. The initial treatment of NS was introduced according to Polish recommendations by Wyszyńska et al. $[23,24]$. All patients received prednisone therapy at a dose of $60 \mathrm{mg} / \mathrm{m}^{2} /$ day (maximum $80 \mathrm{mg} /$ day) on a daily basis for the first 4 weeks. In cases of favorable response to the therapy, administration of prednisone was switched to $60 \mathrm{mg} / \mathrm{m}^{2} /$ every second day and gradually reduced [23]. In all cases of no response to treatment, either a continuation of prednisone therapy (in the first examined period: 19861995) or intravenous methylprednisolone pulses (in the second period examined: 1996-2005) were introduced [24, 25]. The patients' responses to treatment were assessed by means of the following definitions: remission -3 consecutive days of trace or absent proteinuria on the second-morning urine specimen; steroid sensitivity - remission obtained within 8 weeks of the steroid therapy; with a subgroup of late responders - remission obtained within the 4 th and 8 th weeks of corticosteroid treatment; steroid resistance - no response to the initial 8-week steroid treatment, with a subgroup of partial responders - presenting the resolution of edema and a decrease in proteinuria. The minimum follow-up of 6 months was requested and the subsequent steroid response was evaluated by means of the following definitions: relapse- 3 following days with proteinuria; secondary steroid resistanceno response to steroids in a primary steroid-sensitive patient; frequent relapses - two or more episodes of nephrosis within 6 months of the initial response. Blood pressure at presentation was analyzed as well. Accordingly, hypertension was defined as systolic blood pressure (SBP) or diastolic blood pressure (DBP) exceeding the 95th percentile compared with relevant sex, age, and height percentile levels according to the fourth report of the National High Blood Pressure Education Program (NHBPEP) [26]. Microscopic hematuria was defined as five or more red cells per high-power field in a urine sediment. The estimated glomerular filtration rate (GFR) was calculated at the time of presentation according to the Schwartz formula: GFR $=\mathrm{k} \times$ height $(\mathrm{cm}) /$ plasma creatinine $(\mathrm{mg} / \mathrm{dL})$, where $\mathrm{k}$ was equal to 0.45 for infants, 0.55 for older children and adolescent girls, 0.7 for adolescent boys over 13 years of age [27]. Decreased glomerular filtration was defined as GFR $<90 \mathrm{~mL} / \mathrm{min} / 1.73 \mathrm{~m}^{2}$ (the definition was adopted from the Kidney Disease Outcomes Quality Initiative (K/DOQI) guidelines for chronic kidney disease) [28]. 
Pathological condition

Whenever possible, kidney biopsy was performed with parental consent, mainly in steroid-resistant children. In steroid-sensitive children, frequently relapsing NS prior to the introduction of an alternative treatment (alternative to corticosteroids), was the main indication for kidney biopsy. Renal tissues were examined by means of light, immunofluorescence, and electron microscopy. Samples were subject to interpretation by our pathologist with the presence of at least five glomeruli. MCNS was described as the absence of abnormality or a very discreet mesangial matrix expansion on light microscopy. MesPGN was defined as the presence of mesangial matrix expansion and mesangial cell proliferation. FSGS was characterized by the presence of at least one glomerulus with segmental sclerotic lesions, and MPGN was described as the presence of mesangial cell proliferation accompanied by immune deposits along the basement membrane. Finally, MGN was defined as the presence of immune deposits along the basement membrane.

\section{Statistical analysis}

Continuous data were presented as a median and interquartile range, and statistical significance was analyzed using the Mann-Whitney $U$ test. For the comparison of contingency tables the Chi-squared test was used, and in the case of expected numbers less than five Fisher's exact test was used. The statistical significance level was defined as $P<0.05$ (bilaterally). All statistical analyses were performed using the Statistica software platform version 7.1 PL (StatSoft, College Station, TX, USA).

\section{Results}

We identified 215 children with new-onset NS that were admitted to our hospital between 1986 and 2005. The inclusion criteria were met by 178 patients with primary NS. In order to compare the model of NS in two consecutive decades, patients included in the study were divided into two separate groups: Group A-children treated in the first period of 10 years (1986-1995, $n=76)$; Group B-children treated in the second period $(1996-2005, n=102)$.

\section{Characteristics of childhood NS at presentation}

The demographic profile of all patients included in the study is shown in Table 1. Apparently, there were no statistical age and sex distribution differences at the onset of NS between the two groups. Table 2 shows the evidence of symptoms nonspecific for NS. We found no significant difference in
Table 1 Age and sex distribution: Group A (1986-1995), Group B (1996-2005)

\begin{tabular}{llll}
\hline & $\begin{array}{l}\text { Group A } \\
(n=76)\end{array}$ & $\begin{array}{l}\text { Group B } \\
(n=102)\end{array}$ & $P$ value \\
\hline $\begin{array}{l}\text { Median age at onset (years) } \\
\begin{array}{l}\text { Interquartile range of } \\
\text { age at onset (years) }\end{array}\end{array}$ & 2.7 & 3.3 & 0.072 \\
\begin{tabular}{l} 
Male:female ratio \\
\hline
\end{tabular} & $1.0-4.1$ & $2.1-6.0$ & 0.072 \\
\hline
\end{tabular}

the frequency of hypertension and decreased GFR at presentation between the groups. However, we observed an increased frequency of patients with the presence of microscopic hematuria in the second decade examined.

Response to initial corticosteroid treatment of childhood NS

The initial response to corticosteroid therapy was assessed after the first 8 weeks of treatment. Based on the data, we found a statistically significant decrease in the frequency of steroid sensitivity in the latter decade (Fig. 1). Sixty-two out of $64(96.9 \%)$ steroid-sensitive patients from Group A, and 62 out of $70(88.6 \%)$ steroid-sensitive patients from Group $\mathrm{B}$ responded to the corticosteroid treatment within the first 4 weeks $(P=0.1)$. Only 2 out of 64 children on prednisone therapy from Group A (3.1\%), and 8 out of 70 children on methylprednisolone pulses from Group B (11.4\%) met the definition of late responders $(P=0.1)$. Three out of 12 steroid-resistant patients from Group A $(25 \%)$ and 6 out of 32 steroid-resistant patients from Group B (18.7\%) showed symptoms of partial remission $(P=0.69)$. In the case of a relapse, the initial dose of prednisone was introduced in steroid-sensitive patients. No statistical difference in the frequency of secondary steroid resistance was found in the population analyzed. In Group A there were 5 secondary steroid-resistant children (6.57\%), and in Group B there were 4 secondary steroid-resistant children $(P=0.5)$. None of the late responders from Group A, and $1(12.5 \%)$ from Group B became secondary steroid-resistant patients $(P=1.0)$.

Table 2 Clinical and biochemical profile of the presentation: Group A (1986-1995), Group B (1996-2005). SBP systolic blood pressure; $D B P$ diastolic blood pressure; GFR glomerular filtration rate

\begin{tabular}{llll}
\hline & $\begin{array}{l}\text { Group A } \\
(n=76)\end{array}$ & $\begin{array}{l}\text { Group B } \\
(n=102)\end{array}$ & $P$ value \\
\hline $\mathrm{SBP}>95$ th percentile & $37(48.7 \%)$ & $41(40.2 \%)$ & 0.26 \\
$\mathrm{DBP}>95$ th percentile & $33(43.4 \%)$ & $40(39.3 \%)$ & 0.57 \\
$\mathrm{GFR}<90 \mathrm{~mL} / \mathrm{min} / 1.73 \mathrm{~m}^{2}$ & $28(36.8 \%)$ & $26(25.5 \%)$ & 0.1 \\
Microscopic hematuria & $21(27.6 \%)$ & $50(49 \%)$ & 0.004 \\
\hline
\end{tabular}




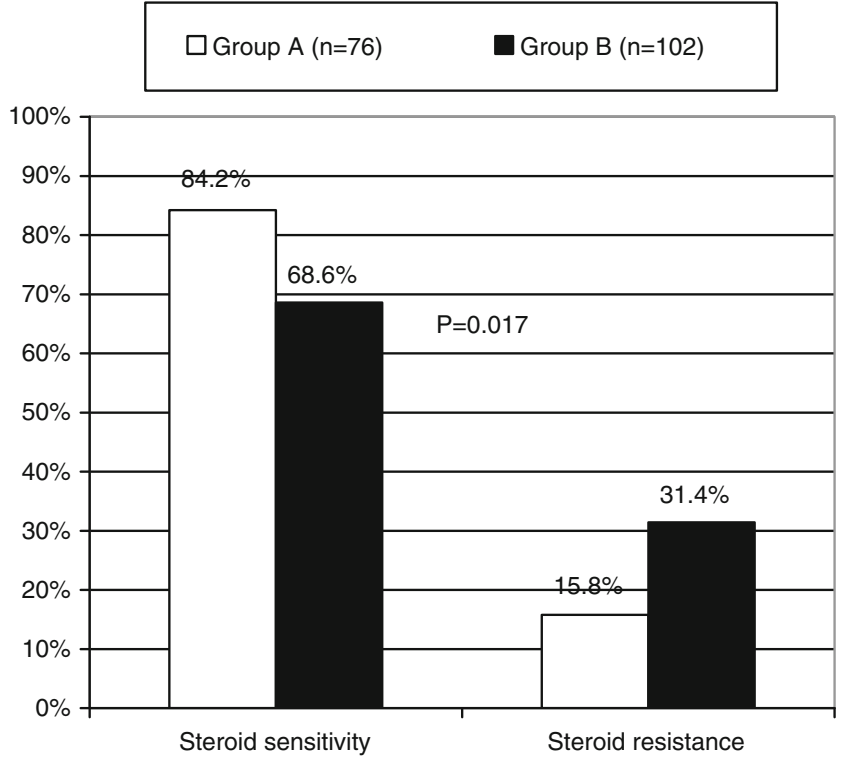

Fig. 1 Response to the initial corticosteroid treatment: Group A (1986-1995), Group B (1996-2005)

\section{Childhood NS histopathology}

Kidney biopsy was performed at a statistically comparable frequency: in 28 patients of Group A (36.8\%) and in 44 patients of Group B $(43.1 \%$; $P=0.4)$ respectively. Comparing Group A and Group B, we found a slight, statistically insignificant change in the histopathology of primary NS toward a decrease in MCNS and an increase in both MesPGN and FSGS in the more recent decade (Table 3). Kidney biopsies in steroid-sensitive patients were usually performed later than in steroid-resistant patients. Therefore, we additionally compared the morphology of primary steroid-resistant children biopsied in a comparable early phase of NS. In the population of steroid-resistant children kidney biopsy was performed in 9 children from Group A (75\%) and in 25 children from Group B $(78.1 \% ; P=1.0)$. The histopathology of steroid-resistant NS slightly changed

Table 3 Histopathology distribution on kidney biopsy: Group A (1986-1995), Group B (1996-2005). MCNS minimal change nephrotic syndrome; MesPGN mesangial proliferative glomerulonephritis; FSGS focal segmental glomerulosclerosis; $M P G N$ membranoproliferative glomerulonephritis; $M G N$ membranous glomerulonephritis

\begin{tabular}{llll}
\hline & $\begin{array}{l}\text { Group A } \\
(n=28)\end{array}$ & $\begin{array}{l}\text { Group B } \\
(n=44)\end{array}$ & $P$ value \\
\hline MCNS & $7(25 \%)$ & $4(9 \%)$ & 0.0095 \\
MesPGN & $13(46.4 \%)$ & $27(61.4 \%)$ & 0.21 \\
FSGS & $5(17.9 \%)$ & $9(20.4 \%)$ & 0.78 \\
MPGN & $2(7.1 \%)$ & $3(6.8 \%)$ & 1 \\
MGN & $1(3.6 \%)$ & $0(0 \%)$ & 0.39 \\
\hline
\end{tabular}

towards the increased incidence of FSGS in the most recent decade; however, it did not reach the level of statistical significance (Table 4).

\section{Discussion}

Childhood NS used to be considered a benign disease that was responsive to corticosteroid therapy, mostly with the morphology of minimal change glomerulonephritis and had a good long-term prognosis [2, 4, 6, 7]. New evidence, however, in recent years, suggests that both the histopathology and the response to therapy for childhood NS might have changed $[8,10-14,16,17]$. Therefore, the purpose of our study was to explore trends in the clinical and histopathological characteristics of primary NS in Caucasian children admitted to a pediatric nephrology center in southern Poland within the two following decades (1986-1995, 76 children; 1996-2005, 102 children). The increase in the number of children with new-onset NS, treated in the second period examined (1996-2005) can be explained by the increase in the number of inhabitants in the referral area. This changed from 3,900,000 before 1999 to 4,700,000 after 1999 owing to the territorial reorganization of Poland. To avoid a referral bias (as the clinic is a referral pediatric nephrology center for the region of Silesia), only children with new-onset untreated NS or children in the very early stages of the treatment process were included in the analysis. The clinical characteristics at presentation did not vary significantly. The high level of incidence of hypertension and decreased renal function could be explained by transient disturbances in fluid balance.

To summarize, one major finding of our study was the discovery of a decreasing rate of steroid sensitivity among patients with primary NS in the latter period. Steroid sensitivity characterized $84.2 \%$ of patients in Group A (19861995). This result was comparable to the corresponding outcome of the ISKDC report $(78 \%)[2,7]$. However, in Group B (1996-2005) steroid sensitivity effects were

Table 4 Histopathology distribution on kidney biopsy in primary steroid-resistant children: Group A (1986-1995), Group B (19962005). MCNS- minimal change nephrotic syndrome, MesPGN- mesangial proliferative glomerulonephritis, FSGS- focal segmental glomerulosclerosis, MPGN- membranoproliferative glomerulonephritis)

\begin{tabular}{llll}
\hline & $\begin{array}{l}\text { Group A } \\
(n=9)\end{array}$ & $\begin{array}{l}\text { Group B } \\
(n=25)\end{array}$ & $P$ value \\
\hline MCNS & $1(11 \%)$ & $1(4 \%)$ & 0.47 \\
MesPGN & $5(55.6 \%)$ & $14(56 \%)$ & 1 \\
FSGS & $2(22.2 \%)$ & $9(36 \%)$ & 0.68 \\
MPGN & $1(11.1 \%)$ & $1(4 \%)$ & 0.47 \\
\hline
\end{tabular}


present in only $68.6 \%$ of patients with primary NS, yielding a significantly lower result. The majority of steroid-sensitive patients entered remission within the first 4 weeks of daily prednisone therapy. The continuation of prednisone therapy over a period of 4 weeks led to remission in 2 patients from the first decade examined, whereas the introduction of methylprednisolone pulses resulted in remission in 8 children from the second decade examined. Evaluating the effects of steroid therapy in childhood NS is rather strict - patients can be either steroid-sensitive or steroid-resistant. However, some authors propose the introduction of the definition of a partial response to the treatment. In our study, we observed a minor, but not statistically significant, increase in the number of partial responders. All of them, despite partial clinical and biochemical improvement, were classified and further treated as steroid-resistant patients. Indicating the increase in steroid resistance in childhood NS, the main finding of our study seems to be consistent with the results of other researchers. For example, Kim et al. [17] described steroid sensitivity in primary NS in only $71 \%$ of children admitted over the period 1994-2003 to two major centers in New Orleans, which is lower than in the ISKDC study. Moreover, Kim et al. reported a high incidence $(16.5 \%)$ of late steroid resistance compared with the ISKDC study (3.3\%) and our own observations (6.57\% and 3.93\%). Both Kim et al.'s study and our analysis showed an inclination toward increasing rates of steroid resistance in childhood NS. However, the study by Kim et al. was compared with the ISKDC project, i.e., a comparison of two different populations. One major benefit of our study is that it is based on the comparison of childhood NS within the same population. Clearly, one question arises as to the reason for the increasing incidence of steroid resistance in childhood NS. Kim et al. suggested that this might be due to the high proportion of African-Americans in their study; however, our study shows the same development within a homogeneous population of Caucasian children. Another hypothesis is that the increasing incidence of steroid resistance in NS might result from changes in the histopathology of NS toward the higher incidence of FSGS. FSGS is a histopathological diagnosis widely identified with the steroid-resistant model of response in NS.

In our study some dynamic trends in the pathology of childhood NS were also present. From kidney biopsies an insignificant decrease in MCNS (from $25 \%$ to $9 \%$ ) and increases in MesPGN (from $46.4 \%$ to $61.3 \%$ ) and FSGS (from $17.8 \%$ to $20.4 \%$ ) were observed in the most recent decade. Unfortunately, not all steroid-resistant patients were biopsied, mainly because of the lack of parental consent. For comparison, in the latter period a comparable number of biopsied steroid-resistant children showed a slight decrease in MCNS (from $11 \%$ to $4 \%$ ) and an increase in FSGS (from $22.2 \%$ to $36 \%$ ) accompanied by an unchanged incidence of
MesPGN (56\%). Nevertheless, none of the results describing trends in histopathology analyzed in our study reached the level of statistical significance. Our results do not contradict the observations published in recent years that show an increasing incidence of FSGS in NS, occurring in both children and adults [8-15, 22].

In the 1994 study by D'Agati, followed by an analysis by Haas et al. 1 year later, the researchers postulated that the incidence of FSGS was rising and that FSGS had become the most popular diagnosis of kidney biopsies in adults with NS [9, 22]. Inspired by these findings, in 1999 Bonilla-Felix et al. [10] published their own results showing a significant increase (from $22 \%$ to $47 \%$ ) in the incidence of FSGS in renal biopsies performed on children with idiopathic NS over a period of 20 years. The authors mentioned that the high proportion of African-Americans in the study could have influenced their results. Gulati et al. and Kari et al. described similar trends related to the presence of FSGS in NS among children living in Asia [11, 13, 15]. In 2003, Filler et al. [12] published a twofold (over a period of 17 years) increase in the incidence of FSGS in children, of which $89 \%$ were Caucasian. On the other hand, in 2002, Orta-Sibu et al. [29] reported that in Hispanic children with NS only $6.5 \%$ revealed FSGS. Clearly, the results of the studies cited above may seem to be inconsistent. Apparently, an ethnic composition of the populations attending certain projects may play a key role in the final outcome. For example, it is widely known that African-Americans are prone to hypertension and FSGS [18-21]. Another factor that might influence results is the subjectivity of the pathologists' assessment and poor representativeness of kidney biopsies. As its name suggests, FSGS is a focal lesion. As such, it might be easily overlooked in small samples, especially if they did not contain juxtamedullary glomeruli [30]. Despite the above-mentioned factors that could affect the results, showing an increase in FSGS in childhood NS, none of the studies proved that the changing pattern of the histopathology of NS is the only reason for the increase in steroid resistance of childhood NS. The explanation for the phenomenon of increasing frequencies of steroid-resistant patients with childhood NS may be more complex, and probably includes the influence of environmental and genetic factors throughout the course of illness. Some childhood steroid-resistant nephrotic syndromes may be due to genetically determined syndromes with late onset, and only molecular screening could allow these patients to be distinguished and prevented from receiving any ineffective therapy [31, 32]. Perhaps the results of our study reveal local trends; however, they indicate that steroid-resistant childhood NS is becoming a growing challenge for both doctors and patients. 
Acknowledgements The authors gratefully acknowledge the assistance of Iwona and Janusz Goldasz in the translation of the article.

Sources of support None.

Open Access This article is distributed under the terms of the Creative Commons Attribution Noncommercial License which permits any noncommercial use, distribution, and reproduction in any medium, provided the original author(s) and source are credited.

\section{References}

1. McEnery PT, Strife FC (1982) Nephrotic syndrome in childhood. Pediatr Clin North Am 89:875-893

2. International Study of Kidney Disease in Children (1978) Nephrotic syndrome in children: prediction of histopathology from clinical and laboratory characteristics at time of diagnosis. Kidney Int 13:159-165

3. Habib R (1993) A story of glomerulopathies: a pathologist's experience. Pediatr Nephrol 7:336-346

4. Churg J, Habib R, White RH (1970) Pathology of the nephrotic syndrome in children. Lancet 20:1299-1302

5. White RH, Glasgow EF, Mills RJ (1970) Clinicopathological study of nephrotic syndrome of childhood. Lancet 1:1353-1359

6. Tarshish P, Tobin JN, Bernstein J, Edelmann CM (1997) Prognostic significance of the early course of minimal change nephritic syndrome. J Am Soc Nephrol 8:769-776

7. International Study of Kidney Disease in Children (1981) The primary nephrotic syndrome in children. Identification of patients with minimal change nephrotic syndrome from initial response to prednisone. J Pediatr 98:561-564

8. Srivastava T, Simon SD, Alon US (1999) High incidence of focal segmental glomerulosclerosis in nephrotic syndrome of childhood. Pediatr Nephrol 13:13-18

9. Haas M, Spargo BH, Coventry S (1995) Increasing incidence of focal segmental glomerulosclerosis among adult nephropathies: a 20 year renal biopsy study. Am J Kidney Dis 26:740-750

10. Bonilla-Felix M, Parra C, Dajani T, Ferris M, Swindford RD, Portman RJ, Verani R (1999) Changing patterns in the histopathology of idiopathic nephrotic syndrome in children. Kidney Int 55:1885-1890

11. Gulati S, Sharma AP, Sharma RK, Gupta A (1999) Changing trends of histopathology in childhood nephrotic syndrome. Am J Kidney Dis 34:646-650

12. Filler G, Young E, Geier P, Carpenter B, Drukker A, Feber J (2003) Is there really an increase in non-minimal change nephrotic syndrome in children. Am J Kidney Dis 42:1107-1113

13. Kari JA (2002) Changing trends of histopathology in childhood nephrotic syndrome in western Saudi Arabia. Saudi Med J 23:317-321

14. Hogg RJ, Silva FG, Berry PL, Wenz JE (1985) Focal segmental glomerulosclerosis in children with idiopathic nephrotic syndrome. A report of the Southwest Pediatric Nephrology Study Group. Kidney Int 27:442-449

15. Kari JA, Halawani M, Mokhtar G, Jalalah SM, Anshasi W (2009) Pattern of steroid resistant nephritic syndrome in children living in the kingdom of Saudi Arabia: a single center study. Saudi J Kidney Dis Transpl 20:854-857
16. Chesney R (2004) The changing face of childhood nephrotic syndrome. Kidney Int 66:1294-1302

17. Kim JS, Bellew CA, Silverstein DM, Aviles DH, Boineau FG, Vehaskari VM (2005) High incidence of initial and late steroid resistance in childhood nephrotic syndrome. Kidney Int 68:12751281

18. Rostand SG, Cross SK, Kirk KA, Lee JY, Kuhlmann A, Amann K (2005) Racial differences in renal arteriolal structure in children with minimal change nephropathy. Kidney Int 68:1154-1160

19. Bakir A, Bazilinski N, Rhee H, Ainis H, Dunea G (1989) Focal segmental glomerulosclerosis. A common entity in nephritic black adults. Arch Int Med 19:49-55

20. Hsu CY, Lin F, Vittinghoff E, Shlipak MG (2003) Racial differences in the progression from chronic renal insufficiency to endstage renal disease in the United States. J Am Soc Nephrol 14:29022907

21. Kalinowski L, Dobrucki I, Maliński T (2004) Race-specific differences in endothelial function: predisposition of African Americans to vascular diseases. Circulation 109:2511-2517

22. D'Agati VD (1994) The many masks of focal segmental glomerulosclerosis. Kidney Int 46:1223-1241

23. Ksiazek J, Wyszyńska T (1995) Short versus long initial prednisone treatment in steroid-sensitive nephrotic syndrome in children. Acta Paediatr 84:889-893

24. Wyszyńska T, Ksiazek J, Uszycka-Karcz M, KobierskaSzczepanska A, Morawska Z, Zoch-Zwierz W (1988) Evaluation of prednisolone pulse therapy in steroid-resistant nephrotic syndrome. A multicenter collaborative study. Contrib Nephrol 67:229-232

25. Murnaghan K, Vasmant D, Bensman A (1984) Pulse methylprednisolone therapy in severe idiopathic childhood nephritic syndrome. Acta Paediatr Scand 73:733-739

26. National High Blood Pressure Education Program Working Group on High Blood Pressure in Children and Adolescents (2004) The fourth report on the diagnosis, evaluation, and treatment of high blood pressure in children and adolescents. Pediatrics 114:555576

27. Schwarz GJ, Haycock GB, Edelmann CM, Spitzer A (1976) A simple estimate of glomerular filtration rate in children derived from body length and plasma creatinine. Pediatrics 58:259-263

28. Hogg RJ, Furth S, Lemley KV, Portman R, Schwarz GJ, Coresh J, Balk E, Lau J, Levin A, Kausz AT, Eknoyan G, Levey AS (2003) National Kidney Foundation's Kidney Disease Outcomes Quality Initiative clinical practice guidelines for chronic kidney disease in children and adolescents: evaluation, classification and stratification. Pediatrics 111:1416-1421

29. Orta-Sibu N, Lopez M, Moriyon JC, Chavez JB (2002) Renal diseases in Venezuela, South America. Pediatr Nephrol 17:566569

30. Ichikawa I, Fogo A (1996) Focal segmental glomerulosclerosis. Pediatr Nephrol 10:374-391

31. Ruf RG, Lichtenberger A, Karle SM, Haas JP, Anacleto FE, Schultheiss M, Zalewski I, Imm A, Ruf EM, Mucha B, Bagga A, Neuhaus T, Fuchshuber A, Bakkaloglu A, Hildebrandt F, Arbeitsgemeinschaft für Pädiatrische Nephrologie Study Group (2004) Patients with mutations in NPHS2 (podocin) do not respond to standard steroid treatment of nephrotic syndrome. J Am Soc Nephrol 15:722-732

32. Feber J, Filler G (2006) Nephrotic syndrome in children: should we always use steroids for the initial therapy. Przegl Lek 63:12-14 